\title{
Need of the Regulation for Profit Percentage Investment by Pharmaceutical Companies in New Drug Discovery Research from the Various Local Traditional Medicinal and Plant Systems
}

\author{
Bhattarai MD' \\ 'National Academy of Medical Sciences, Bir Hospital, Kathmandu, Nepal.
}

\begin{abstract}
In the modern medical systems the active pharmacological ingredients, effective against any disease is identified, purified and studied for its various effects and side-effects whereas it is not so in the traditional systems. Therefore, it is not surprising that safety concerns have often been raised about the traditional medical products. The major issue now, is to make appropriate situation with basic supports to bring all the available experts and resources together for the identification, purification, and study of efficacy and safety of the active molecules of the popular traditional medicines. Government and public sectors in the countries with such rich traditional medicinal and plant systems have related experts, but they also have much hurdle regarding recruitment and retention of expert human resources, getting fund, purchase and maintenance of equipment, bureaucratic formalities and others. The pharmaceutical companies have basic laboratories with related infrastructure and human resources as well as interest about bringing the drug molecules. To bridge the gap, there is a need of the regulation which will make the pharmaceutical companies to invest certain percentage of their profit in the field of research to identify new drug molecules and to study their effects. It is just not an issue of discovering the active molecule but also of creating the concept and culture of research, purity and quality of drugs, safety of people, and future direction of the human society.
\end{abstract}

Keywords: drug development; investments; medicinal plants; pharmaceuticals; public-private participation; research; traditional medicine.

\section{INTRODUCTION}

Nepal is famous for its biodiversity, which includes not only ecosystem diversity but also species and genetic diversity. The altitudinal variation is from 68 metres at Mahottari Districts to 8848 metres at Mount Everest. This is probably the largest altitudinal variation in the world within a narrow width of merely $130 \mathrm{~km} .{ }^{1}$ The climate in Nepal ranges from hot monsoon, tropical to arctic. The extreme variation of climate favors multiple habitats, flora and fauna in this small country with only about 150 thousand square kilometer area. There are about 136 ecosystems present here. There are about 1500 genera and 6000 species of plants. There are nearly a thousand types of birds and more than 6000 types of moths. From time immemorial many medicinal plants are well known in Nepal. Ayurvedic medicine is a system of traditional medicine native to this continent ${ }^{2}$ and a form of alternative medicine. Ayurveda system is chiefly based on the use of medicinal plants. ${ }^{1}$ Nepal is rich in traditional medicinal systems including Ayurveda, Amchi, Unani, Naturopathy, Homeopathy and others and most such traditional medicinal systems relies heavily on the plant products from the Nepal Himalaya. ${ }^{1}$

Correspondence: Dr. Madhur Dev Bhattarai, National Academy of Medical Sciences, Bir Hospital, Kathmandu, Nepal. Email: mdb@ntc.net. np 
Each of the sites where the world's four greatest civilizations started had its own medicine. The medicines of Egyptian and Mesopotamian civilization progressed as Western and Arabian medicine via Greek and Roman civilizations, whereas that of the Indus civilization evolved in Ayurveda medicines, and that of the Yellow River civilization into Chinese medicine and Kampo medicine practiced mostly in Japan. ${ }^{1}$ But later with the decline of these civilizations, the researches in their respective medicine system naturally got halted. Many of the medicines, e.g. digitalis, of the modern medicine are also well known for their discovery from plants. Then what is the major difference between the modern and the traditional medicinal systems?

One of the major differences between the modern and other systems is that in the modern medical systems the active pharmacological ingredient effective against any disease is identified, purified and studied for its various effects and side-effects. In other traditional systems such practice could not be continued due to the decline of the related civilizations. Safety concerns have been raised about the traditional medical products. Studies in the US have reported that about $20 \%$ of Ayurvedic treatments tested contained toxic levels of heavy metals such as lead, mercury and arsenic. Other concerns include the use of herbs that contain toxic compounds and the lack of quality control in Ayurvedic facilities. ${ }^{3,4}$ It is well known that everything under the sun including the sun have side-effects, the well known example of which is that diabetes can be called one side-effect of the food. To minimize the side-effects, the focus of modern medical system is to purify the active ingredient available from any source, so that it can be used safely in the human being after its safety and efficacy studies. Research to identify, purify, and study for various effects and side-effects of the active pharmacological substance of the local traditional medicines of the country is, thus, the obvious priority need. If we can do that in Nepal with its rich biodiversity and traditional medicinal systems, we could discover many new drugs useful for the mankind and also generate income for the country. How can we make this happen in our country and the region? Can we just wait for government institutions to conduct such research?

\section{CHALLENGES}

Government sectors usually have much hurdle regarding recruitment and retention of expert human resources, getting fund, purchase and maintenance of equipment, bureaucratic formalities and even corruption. For such research, the experts and institutions in various fields like chemistry, pharmacology, botany, medical practitioners in modern, Ayurveda and other traditional medicine systems, researcher, biostatisticians and others are as such already present and bright younger generations are coming up. There are increasing funds available from international resources on various diseases like HIV/AIDS, tuberculosis, malaria, non-communicable diseases (NCD) and others. Further collaborators from different regional and other countries are showing interest in the capacity building for such research. For the experts and collaborators to start, we have also to consider their basic requirements, like laboratory support and expertise on its quality, secretarial support including for electronic media and communication, expertise on proposal making, supporting administration and the interest by the administration of the institutions. Thus the major issue is now is to make appropriate situation with basic supports to bring all these experts and resources together and to concentrate on the real work. How do we bridge the gap?

In the industrialized countries, researches on new molecules are done also by the pharmaceutical companies. The pharmaceutical companies are as such dealing with the drugs and their manufacturing and quality. In our country and region as well, the basic laboratories with related infrastructure and human resources as well as interest about bringing the drug molecules are with the pharmaceutical companies. The participation in the research of new molecules is related to the job of the pharmaceutical companies and help to strengthen them building further their capacity. Apart from at least improving the quality of their laboratory utilizing their existing resources and experts to the full, there are much potential benefits to the pharmaceutical companies. It will bring them into contacts with national and international experts and collaborators and increase their horizon and the quality of their working atmosphere. It may increase their manufacturing capacity. Apart from such capacity building, networking and quality improvement, societal responsibility is also as such considered as one of the basic business principle. It would be a typical and useful example of the Public-Private Participation (PPP) with benefits to the both sides and the people.

Identification and isolation of active ingredient molecules and providing the evidence of their efficacy and safety profile is no doubt a huge task. But the whole process itself will help not only to increase the quality laboratories in the pharmaceutical companies aiding to their manufacturing capacity but also to increase the research atmosphere in the various institutions in the country and the region with provision of job opportunity and income source for the experts in the basic sciences. It will thus support the education and research of the basic sciences as well. It is just not 
an issue of discovering the active molecule but also of creating the concept and culture of research, purity and quality of drugs, safety of people, and future direction of the human society. Moreover, if such research is encouraged in the community by participation of the maximum number of experts, the probability of discovering new drug increases in this region with such rich plant varieties and the historical traditional medicinal systems. The experts and scientists in the country and region will get the opportunity to work and may even get the prestigious awards like Nobel Prize in the field of medicine and chemistry! There is really a need of a regulation in the country, and the region as well, that "Every pharmaceutical company should contribute $10-20 \%$ of their net profit in the field of research of new molecules and drug and active ingredients from the various local traditional medicinal and plant systems". How much exact percentage of net profit to keep in the regulation needs to be worked out by the related financial experts in the field. Considering the rich biodiversity and plant systems and traditional medicinal systems, the regulation should of course be clear to specify the research of the new molecules and drugs, not just on any research only.

\section{WAY FORWARD}

The regulation will make the pharmaceutical companies to invest certain percentage of their profit in the field of research to identify new drug molecules and to study their effects. The different companies can collaborate with each other to increase their expertise and funds. The medical and basic science experts in the field in the government organizations and universities in the country and from abroad can contribute in such new drug discovery research. With such strong base they can apply to the various global funds for research. The only need today is thus to pass regulation in the country that every pharmaceutical company should contribute certain percentage of their profit in the field of new drug discovery from the various local traditional medicinal and plant systems. Then it would be no wonder that we can also discover new drugs useful for the human society and our country and the region get recognized in the world in this area as well. The associations of pharmaceutical companies, chemistry, botany, traditional and modern medicine, research experts, and others and Health Research Council may raise the issue to pass such legislation.

\section{REFERENCES}

1. Baral SR, Kurmi PK. A Compendium of Medical Plants in Nepal. Kathmandu: Sharma/WWF/IUCN; 2006.

2. Chopra, Ananda S. Ayurveda. In Selin, Helaine. Medicine Across Cultures: History and Practice of Medicine in Non-Western Cultures. Norwell, MA: Kluwer Academic Publishers; 2003. P .75-83.
3. Saper RB, Phillips RS, Sehgal A, Khouri N, Davis RB, Paquin J, et al. Lead, mercury, and arsenic in US- and Indian-manufactured Ayurvedic medicines sold via the Internet. JAMA. 2008 Aug 27;300(8):915-23.

4. Valiathan MS. Ayurveda: Putting the House in Order. Current Science. 2006;90(1):5-6. 